
Article

\title{
Role of measurement of gestational sac, yolk sac volumes and retrochorionic blood flow by 3D ultrasound as a predictor of pregnancy outcome in the first trimester
}

\author{
Asmaa M Kamel ${ }^{1}$, Doaa M Effat ${ }^{2}$, Lamiaa M Yosry ${ }^{2}$ \\ ${ }^{1}$ Obstetrics and Gynecology Department, Al-Saf central hospital, Giza, Egypt. \\ 2 Obstetrics and Gynecology Department, Faculty of Medicine for Girls, Cairo, Al-Azhar University, Egypt.
}

\section{ABSTRACT}

Background: to assess the possibility of hazard in early pregnancy, the first trimester 3D ultrasound can be used.

Objective: to evaluate the role of 3D ultrasound measurements of yolk sac volume (YSV), gestational sac volume (GSV) and retrochorionic blood flow in predicting possibility risks in pregnancy during the first trimester.

Methodology: This prospective cohort study carried out at Al-Zahraa Hospital included 100 pregnant women aged (2035 years) at (5-11 weeks) of conception attend the outpatient obstetric clinics for antenatal care during a study period of one year (Dec.2018 and Dec.2019). They were selected by convenient sample and divided into; repeated pregnancy failure group (50) patients and normal control group (50) persons with the same criteria. Patients included in the study were offered 3D ultrasound and afterwards they were followed up till twenty weeks to predict pregnancy result.

Results: The ROC curve was used to identify the area under the curve for retrochorionic arteries (RI) sensitivity was $(84.0 \%)$; for gestational sac volume (77.0\%); for yolk sac volume (71.0\%) and for crown rump length $(52.0 \%)$.

Conclusion: First trimester 3D ultrasound assessments of GSV, YSV and retrochorionic blood flow give an accurate method for predicting outcome of pregnancy.

JRAM 2021; 2(1): 54-62

Keywords: Ultrasound, retrochorionic, blood flow, gestational sac volume, volume of yolk sac, pregnancy outcome.

Submission Date: 17 August 2020

Acceptance Date: 9 September 2020

Corresponding author: Asmaa M. Kamel, obstetrics and gynecology department, Al-Saf central hospital, Giza, Egypt.

Tel: 01129051265 E-mail: asmaaeyadroma@gmail.com

Please cite this article as: Kamel AM, Effat DM, Yosry LM. Role of measurement of gestational sac, yolk sac volumes and retrochorionic blood flow by3D ultrasound as a predictor of pregnancy outcome in the first trimester. JRAM 2021; 2 (1): 54-62. DOI: $10.21608 /$ jram.2020.36424.1073

\section{INTRODUCTION}

The initial fetal ultrasound scan is crucial for demonstrating fetal viability, estimation of gestational fetal age and early detection of fetal anomalies in the childbirth ${ }^{[1]}$ The first embryonic constitution in the gestational sac is Yolk sac. It is seen often as a small, anechoic region and degenerating between 5th and 12th weeks of pregnancy. ${ }^{[2]}$ At 4-7 embryonic weeks the yolk sac (YS) achieves its maximum functionality. ${ }^{[3]}$ This more and more increases in linear size until it is 10 weeks old. The YS slowly degenerates and is no longer known after 12 weeks of conception as its role and vascularity decline. ${ }^{[4]}$

Ultrasound measurements of fetal crown-rump length (CRL) are suggested between $7+0$ and $13+6$ weeks conception to date accurate spontaneously conceived pregnancies. ${ }^{[5]}$ Doppler ultrasound provide a noninvasive device for testing placental blood gush and placental susceptibility to infectious diseases on the maternal and fetal side of the placenta ${ }^{[6]}$. The present study attempts to estimate pregnancy outcomes by 3dimensional ultrasound in the projection of gestational sac, yolk sac and retrochorionic blood flow.

\section{PATIENTS AND METHODS \\ Design and setting}

This prospective cohort study conducted over a period of one year (between Dec 2018 and Dec 2019), at Al Zahraa Hospital for antenatal care during the first trimester, on pregnant women who attending the outpatient obstetric clinics. Study protocol was approved by IRB committee of faculty of medicine "girls" Al-Azhar university (IRB number: 202008331). All the necessary approvals for carrying out the research were obtained. Participation in the study was voluntary. 
The inclusion criteria were pregnant women who their age from 20 to 35 years at (5-11 weeks) of gestation; have regular cycles prior to pregnancy without using hormonal contraceptives during three cycles from pregnancy, having excellent obstetric history.

The exclusion criteria were patients below 20 years old or greater than 35 years; gestational ages 14 weeks or older; irregular cycles before pregnancy periods; patients with history of receiving hormonal contraceptives for three cycles before present pregnancy; or patients with poor obstetric history; and patient on drugs or with comorbidity.

\section{Sampling technique \\ -Sample type}

Convenient sample was adopted to collect the studied patients; all pregnant women who met the inclusion criteria and accept to participate in the study were included.

\section{-Sample size}

MedCalc @ Version 12.3.0.0 of "Ostend, Belgium" program was used to estimate the sample volume, the statistical computer based on an interval of $95 \%$ confidence and an estimated power of $80 \%$. Babinszki et al ${ }^{[7]}$, showed that mean importance of crown-rump length (CRL) in aborted group 6.6 \pm 2.9 compared nonaborted group 15.9 \pm 7.2 , with p-value $<0.05$ significant; For this study, it can be relied on the statement, based on these values, the sample size was determined to achieve a minimum sampling size of 95 instances. If the 5 percent drop-out ratio is assumed, the sample volume is 50 cases per group: cases with frequent pregnancy loss group $(n=50)$ and cases without repeated pregnancy loss group $(n=50)$.

\section{Study tools}

The entire history of medicine (Personal, Menstrual and Obstetric) was present for all participants. Last menstrual period gestational age has been calculated. The abdominal ultrasound and tri-dimensional ultraecho detection, sack volume, volume of a gestation sack and blood flow evaluation was performed in all participants, as well.

Ultrasound examinations were done using Madison's ACCUVIX XQ apparatus (Seoul, Korea) and GE Healthcare's VOLUSON E6 apparatus. every tolerant was examined only one time. Volumetric analysis has been done offline. Primary is the determination of the CRL using 2D real time ultrasound (Results of 5-11 to 7-11 weeks of gestation are estimated), yolk sac diameter (the largest internal to internal diameter), mean gestational sac diameter, trophoblastic site and embryonic heart rate. In this study we used the turning VOCAL method for volume calculation.

After converting to $3 \mathrm{D}$ mode, the region of interest (ROI) box was positioned over the whole gestation sac. The scanning angle was used to between forty and sixty degrees according to the time of conception. to take a better quality, harmonic method was used. Onetime scanning is performed; the gestational sac will show on the screen automatically as three vertical orthogonal planes (axial, sagittal and coronal) at the same time.

The sagittal avion was designated as the indicator plane and the point of indication was centrally located. A horizontal alignment of the biggest axis of the gestative sac has rotated the sagittal plane along the $y$ axis. A $30^{\circ}$ turning angle is on the VOCAL button and a manually arranged caliper is placed on the top and bottom extremities and the unit without a human intervention shows the reconstructed picture and its volume after having obtained 6 sequential plans. We chose sagittal plane as suggestive plane and we were scanning it to obtain the biggest axis for yolk sac measurement (Sagittal, Axial and Coronal), for yolk sac volume (YSV). Then an enlarged photo was used, stimulating the yolk sac to the center of the aircraft. A $30^{\circ}$ rotation angle and manual set-up were used to activate the VOCAL button. Calipers were placed on the upper and lower limbs and after six sequential planners the yolk sac with its volume in $\mathrm{cm} 3$ showed the equipment without human intervention as a $3 \mathrm{D}$ figure.

A Blood-Gush-Impedance from the uterine RA and spiral arteries was assessed with a computerized vaginal ultrasound procedure with an integrated pulsed Doppler vaginal scanner $(5.0 \mathrm{MHz})$. Because RAs and spiral arteries are in the lower extremity of uterine artery crossing the myometrium near the endometrium a mid-sagittal part of the uterus has been achieved and RAs in the myometrial medium have been identified. In a gestational sac, trophoblastic tissue was known as a high echoic building with plenty of blood flow in the endometrium-myometrium point. In myometrium near trophoblastic tissue, RA blood flow was predictable. Determine RA blood flow pattern for pulsating color signals in the myometrium.

The Doppler range gate functional and the pulsed Doppler function was activated to evaluate the flow rate of blood once area with the greatest color intensity was chosen. The average of 3-5 cardiac cycles was selected for resistance index (RI) calculation after confirmation of the constant waveforms; the difference between the maximum systolic blood flow speeds and the minimum diastolic flow speeds was divided by the peaking systolic flow speeds. For the estimation of blood flow impedances, we used a resistant index (RI). (RI) of a 0.55 or greater than for any site was considered atypical, as that was the high limit for resistance in a subsequently published study of normal pregnancies.

Patients report on was continued for twenty weeks of pregnancy for the event of normal or abnormal pregnancy events such as continuity and miscarriage.

\section{Statistical analysis}

Release 20.0 (SPSS, Chicago, U.S.) was the statistical program for social science, which analyzed the reports. 
Quantitative results expressed as mean and standard deviation (SD). Qualitative data was transmitted as frequency and percentage. Significant P-value was < 0.05 and a non-significant $\mathrm{P}$-value was $>0.05$. Independent t-test were used to check the relevance of two means among groups. Chi-square (x2) test was used to measure the proportions between qualitative parameters. To evaluate the degree of association between two sets of variables the Pearson correlation code coefficient (r) was used. The analysis of the ROC was used to determine the general predictivity of the parameter and to identify the best cut-off value with sensitivity and the gold stander was calculated using outcome data of studied patients (abortion or continuation of pregnancy).

\section{RESULTS}

Together group' mean age was nearly equal. Highly statistically significant increase was in number of previous abortions mean value in cases group comparing with the control group, but no statistically significant difference between both groups according to (parity, BMI, Gestational age) (table 1).
Regarding the outcomes, the risk of abortion in the first group was $36 \%(18 / 50)$ and in the second group $10 \%(5 / 50)$. The relative risk for abortion outcome was $3.600(0.36 / 0.10)$ that there is a 3.6-fold increased risk of abortion in the cases with frequent pregnancy loss group, and this statistically significant $(\mathrm{P}=0.007)$ (table 2).

According to ultrasound findings in aborted study cases and aborted control were showed that all measurements were better in control group than case group except Yolk Sac Volume with statistically significant difference between case and control groups according to CRL and RI. (P-value 0.018; P-value 0.010) (table 3).

Ultrasound findings in continued study cases and continued control were showed that all measurements were good in control than cases with statistically significant difference in RI only (P-value 0.03) (table 4)

Table (1): Distribution of obstetric data among the studied two groups

\begin{tabular}{|l|c|c|c|}
\hline \multicolumn{1}{|c|}{ Obstetric data } & Cases $(\mathbf{n = 5 0})$ & Controls (n=50) & p-value \\
\hline Age Mean \pm SD (Range) & $27.97 \pm 3.92(20-35)$ & $27.68 \pm 3.96(20.3-34.4)$ & 0.668 \\
\hline Number of previous abortions* & $3.30 \pm 1.60(1-5)$ & $0.08 \pm 0.35(0-2)$ & $0.001 * *$ \\
\hline Mean \pm SD (Range) & $1.32 \pm 0.87(0-3)$ & $1.93 \pm 1.05(1-4)$ & 0.188 \\
\hline Parity* (Mean \pm SD) & $28.80 \pm 1.25(25.4-31.3)$ & $28.70 \pm 1.15(26.2-30.3)$ & 0.596 \\
\hline BMI [wt/(ht)^2] Mean \pm SD (Range) & $8.20 \pm 0.99(7-10)$ & $8.50 \pm 1.09(7-10)$ & 0.145 \\
\hline Gestational age (wks) Mean \pm SD (Range) & *Significant p value is $\leq 0.05$, independent sample t test of significance & \\
\hline
\end{tabular}

Table (2): Comparison of pregnancy outcome between case group and control group

\begin{tabular}{|c|c|c|c|c|c|c|c|}
\hline \multirow[b]{2}{*}{ Outcome } & \multicolumn{2}{|c|}{ Cases $(n=50)$} & \multicolumn{2}{|c|}{ Controls $(n=50)$} & \multicolumn{3}{|c|}{ Relative Risk } \\
\hline & No. & $\%$ & No. & $\%$ & $z$-test & p-value & $\begin{array}{c}\text { RR (95\% } \\
\text { C.I.) }\end{array}$ \\
\hline Aborted & 18 & $36.0 \%$ & 5 & $10.0 \%$ & \multirow{3}{*}{2.759} & \multirow{3}{*}{$0.007 *$} & \multirow{3}{*}{$\begin{array}{c}3.600 \\
(1.449-8.944)\end{array}$} \\
\hline Continue & 32 & $64.0 \%$ & 45 & $90.0 \%$ & & & \\
\hline Total & 50 & $100.0 \%$ & 50 & $100.0 \%$ & & & \\
\hline
\end{tabular}

Table (3): Comparison between cases group and control group according to ultrasound finding in aborted patients

\begin{tabular}{|l|c|c|c|c|}
\hline \multicolumn{1}{|c|}{ Ultrasound Finding } & \multicolumn{2}{|c|}{ Aborted } & (ases group \\
Crown-Rump Length (CRL) & $16.26 \pm 6.19$ & $19.21 \pm 4.85$ & 2.466 & $0.018^{*}$ \\
\hline Control group & t-test & p-value \\
\hline Gestational Sac Volume (GSV) & $16.83 \pm 8.15$ & $18.78 \pm 4.98$ & 1.314 & 0.338 \\
\hline Yolk Sac Volume (YSV) & $0.15 \pm 0.04$ & $0.13 \pm 0.05$ & 0.534 & 0.137 \\
\hline Retro Chorionic Arteries (RI) & $0.55 \pm 0.09$ & $0.50 \pm 0.09$ & 2.906 & $0.010^{*}$ \\
\hline
\end{tabular}

Significant $\mathrm{p}$ value is $\leq 0.05$, independent sample $\mathrm{t}$ test of significance 
Table (4): Comparison between case group and control group according to ultrasound finding in continued pregnancy cases

\begin{tabular}{|c|c|c|c|c|}
\hline \multirow[b]{2}{*}{ Ultrasound Finding } & \multicolumn{2}{|c|}{ Continue } & \multirow[b]{2}{*}{ t-test } & \multirow[b]{2}{*}{ p-value } \\
\hline & $\begin{array}{c}\text { Cases group } \\
\quad(n=32)\end{array}$ & $\begin{array}{c}\text { Control group } \\
\qquad(n=45)\end{array}$ & & \\
\hline Crown-Rump Length (CRL) & $22.86 \pm 8.70$ & $26.50 \pm 5.47$ & 0.394 & 0.486 \\
\hline Gestational Sac Volume (GSV) & $38.93 \pm 13.30$ & $38.60 \pm 15.48$ & 1.467 & 0.378 \\
\hline Yolk Sac Volume (YSV) & $0.12 \pm 0.05$ & $0.15 \pm 0.09$ & 0.578 & 0.149 \\
\hline Retro Chorionic Arteries (RI) & $0.48 \pm 0.09$ & $0.44 \pm 0.07$ & 2.518 & $0.03 *$ \\
\hline
\end{tabular}

Significant $\mathrm{p}$ value is $\leq 0.05$, independent sample t test of significance

Receiver operator characteristics (ROC) curves were constructed for ultrasound finding indices of (RI, GSV, YSV and CRL) as predictors of abortion in studied women and was calculated using outcome data of studied patients (abortion or continuation of pregnancy) as diagnostic tool. All the ultrasound indicators were significant predictors as indicated by the substantially great AUC region, the RI being the most important predictor (Figure 1). Nevertheless, the relation between CRL and abortion production was not significant. Table (5)

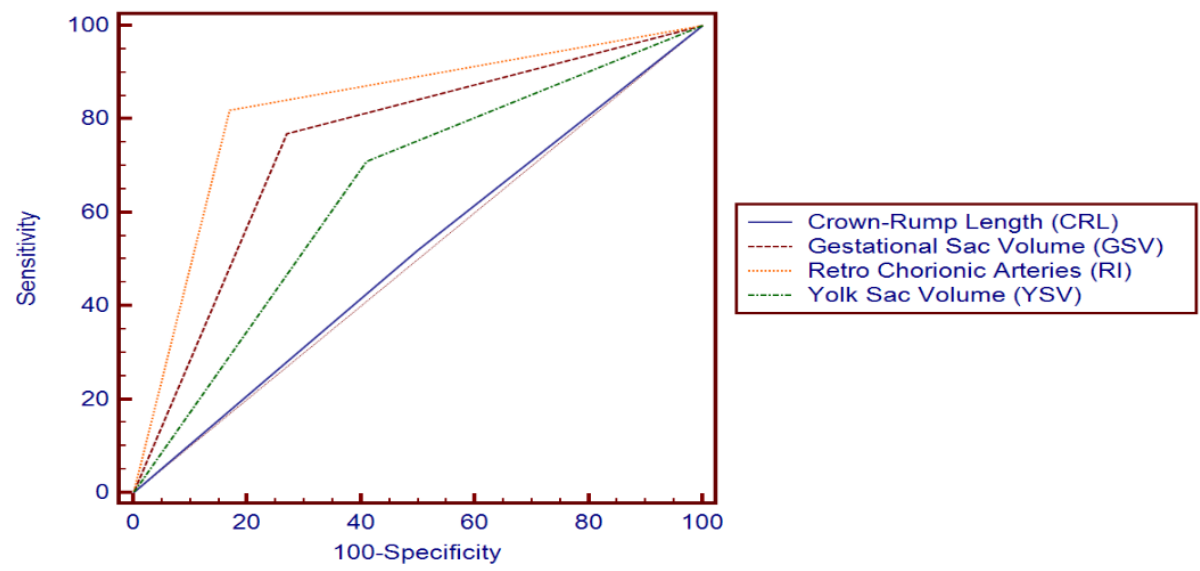

Figure (1): ROC curve for prediction of abortion using the 3D ultrasound finding among the studied women.

Table (5): Curve for the prediction of abortion via the 3D ultrasound identification of the receiver functions (ROC)

\begin{tabular}{|l|c|c|c|c|c|c|c|}
\hline \multicolumn{1}{|c|}{ Ultrasound Finding } & Cut-off & Sen. & Specificity. & PPV & NPV & AUC \\
\hline Retro Chorionic Arteries (RI) & $>0.513$ & $84 \%$ & $83 \%$ & $83.2 \%$ & $83.8 \%$ & $83.5 \%$ \\
\hline Gestational Sac Volume (GSV) & $<18.971$ & $77.0 \%$ & $73.0 \%$ & $74.1 \%$ & $76.4 \%$ & $75.0 \%$ \\
\hline Yolk Sac Volume (YSV) & $>0.144$ & $71.0 \%$ & $59.0 \%$ & $63.4 \%$ & $67.0 \%$ & $65.0 \%$ \\
\hline Crown-Rump Length (CRL) & $<17.204$ & $52.0 \%$ & $50.0 \%$ & $51.2 \%$ & $52.4 \%$ & $51.0 \%$ \\
\hline
\end{tabular}

Sen: Sensitivity -Spe: Specificity- PPV: Positive predictive value - NPV: Negative predictive value - AUC: Area Under Roc curve.

A)

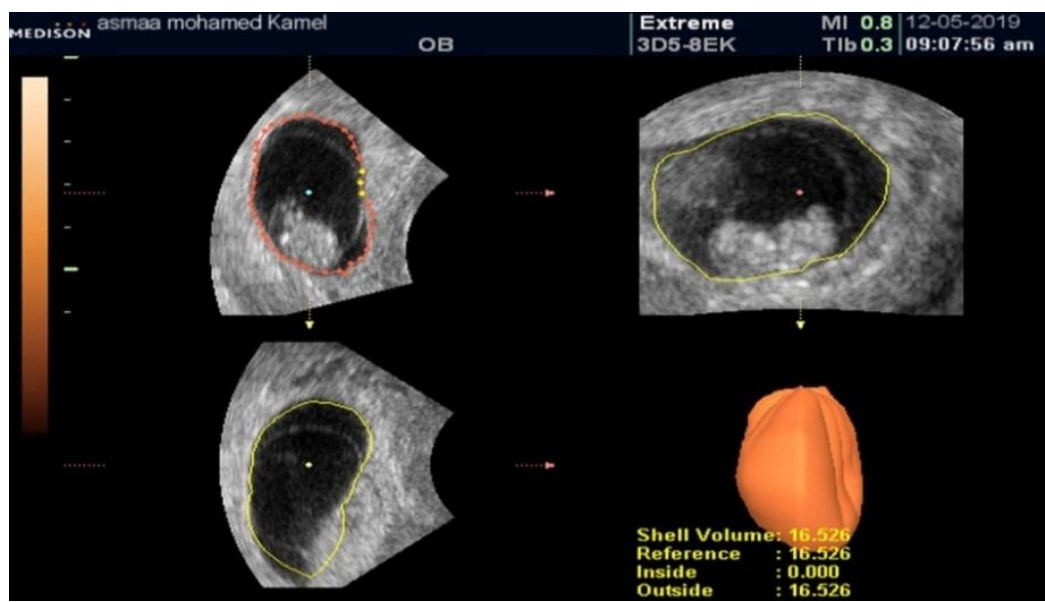


B)

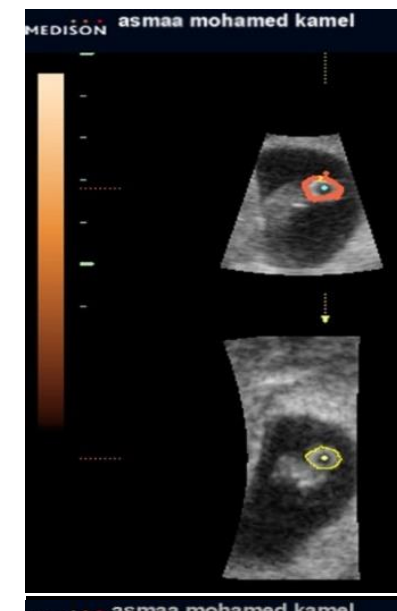

OB

Extreme
3D5-8EK

\begin{tabular}{l|l|l|l} 
MI 0.7 & $12-05-2019$ \\
TIb 0.3 & $10: 14: 30 ~ a m$
\end{tabular}

C)

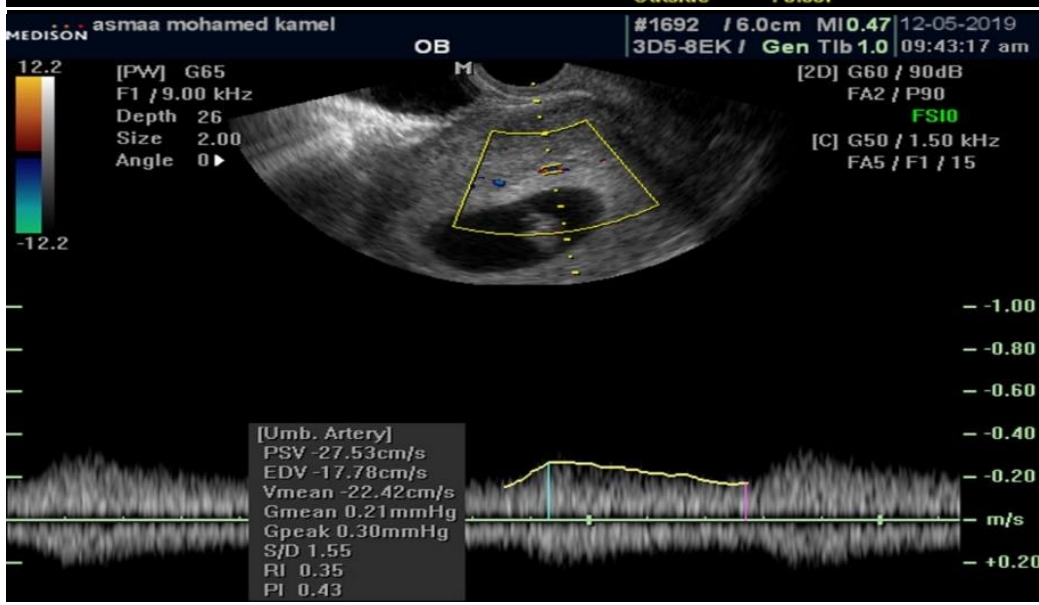

Figure (1): For normal 3D ultrasound finding in a case of control group. A) Gestational sac volume measurement in a case of the control group. B) Yolk sac volume measurement in a case of the control group. C) Doppler ultrasound measurement of retrochorionic blood flow (RI) in a normal pregnancy in a case of the control group.

A)

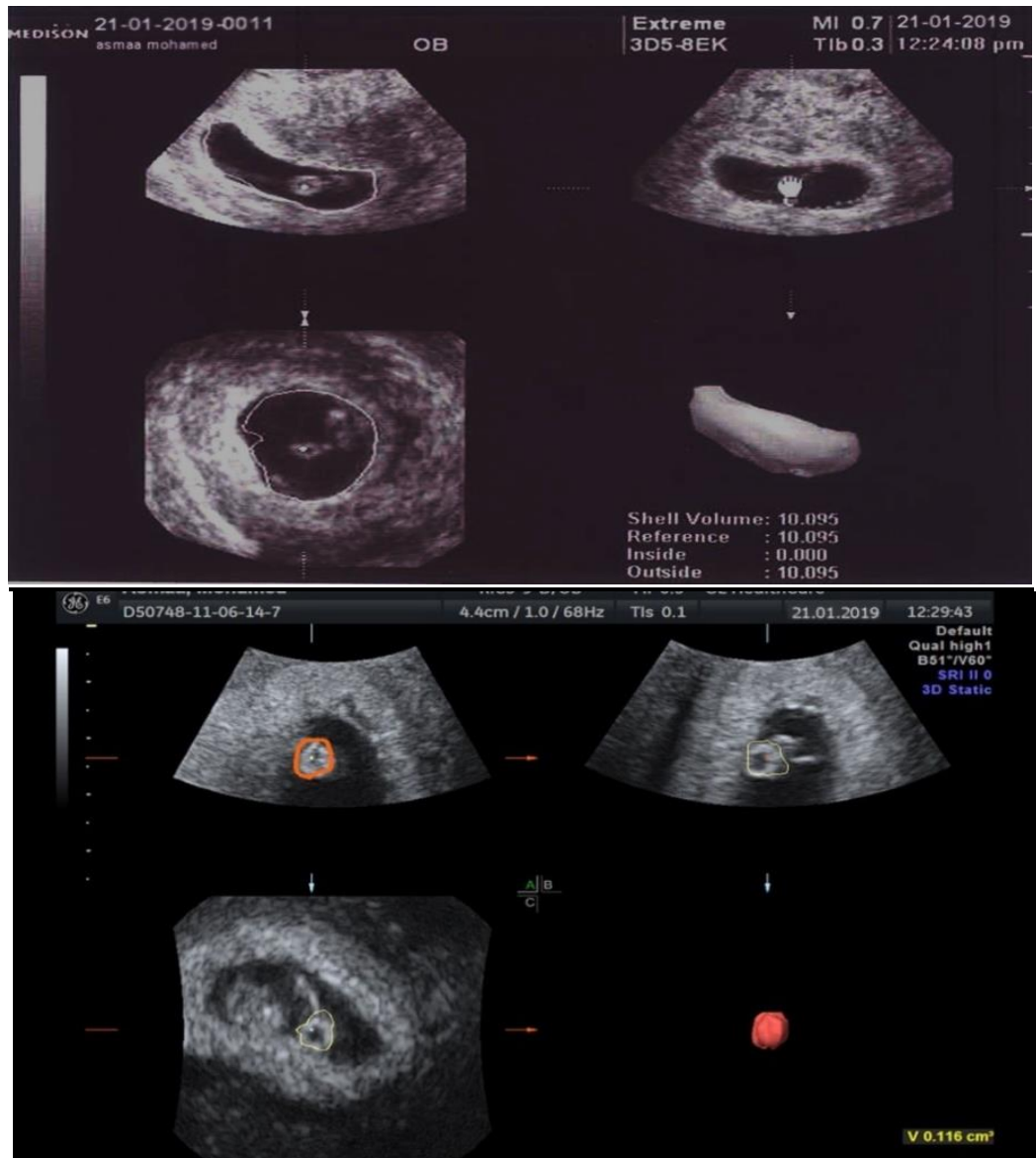

B) 
C)

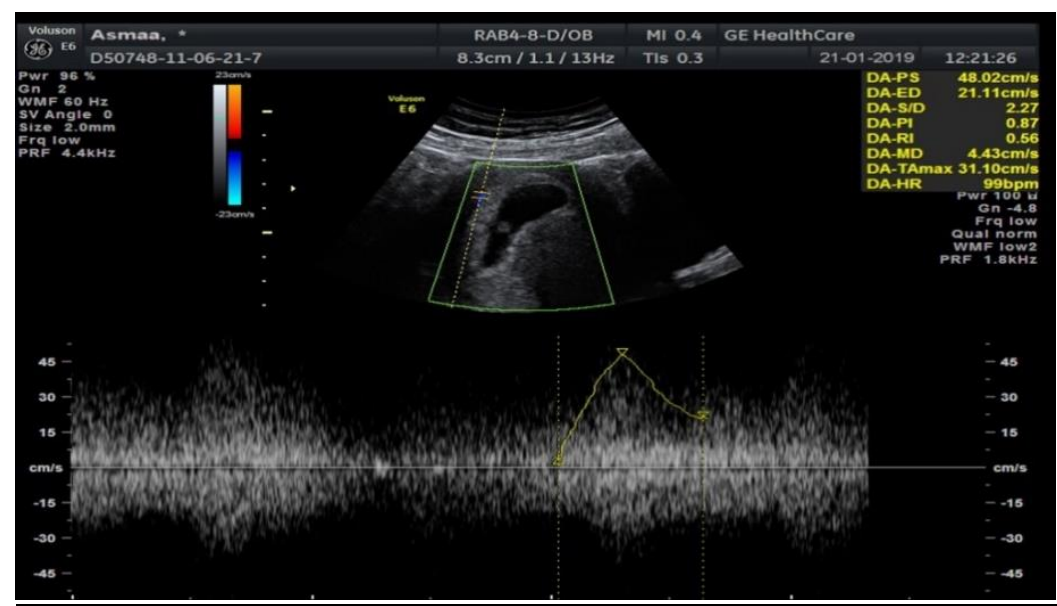

Figure (2): For abnormal 3D ultrasound finding of a studied case of the cases group. A) Gestational sac measurement of abnormal pregnancy in a studied case in case group. B) Yolk sac volume measurement in abnormal pregnancy in a studied case in case group. C) Doppler ultrasound for measurement of retrochorionic blood flow (RI) in abnormal pregnancy in a studied case in case group

\section{DISCUSSION}

In the present study we measured some parameters detected in the first trimester by 3D ultrasound demonstrated to be prognostic for pregnancy result. Different parameters such as GSV, YSV ${ }^{[8]}$ and the relationship between the gestational sac and the average size of the CRL were considered valuable ultrasound markers in early pregnancy ${ }^{[9]}$.

The present study results showed high statistically significant difference between studied case group and control group concerning previous abortions number (p-value <0.001); number of previous abortions was higher in studied cases. This was consistent with Moradan and Forouzeshfar ${ }^{[10]}$, as spontaneous abortion occurred in $14(63.63 \%)$ cases. In the control group, spontaneous abortion was noted in $6(3.55 \%)$. There was a statistically significant difference in abortion rates between the two groups $(\mathrm{p}=0.000)$.

There was no statistically significant difference between studied group cases and control group regarding BMI. The mean BMI was $28.80 \pm 1.25$ and in control group was $28.70 \pm 1.15$. These results agree with Bellver et al. ${ }^{[11]}$ findings who confirmed that obesity (BMI $>/=30$ ) was an independent risk factor for spontaneous abortion. There were significant differences in abortion rates between the obese $(38.1 \%)$, and the normal $(13.3 \%)$ and overweight $(15.5 \%)$ groups. These results disagree with Alemu et al. ${ }^{[12]}$ women in study group had significantly higher BMI (24.83 \pm 2.09$)$ than control group (22.21 \pm 2.54 , $\mathrm{p}=0.001)$. There are potential limitations to consider when interpreting these results. As we need to perform studies on larger number of cases to find out the influence of higher BMI on pregnancy outcomes in first trimester mostly on abortion.

Results of the current study revealed that the mean gestational age was $8.20 \pm 0.99$ in study group cases and $8.50 \pm 1.09$ in control group. There was no statistically significant difference. Other studies as Kazemier et al.
${ }^{[13]}$ found mean GA of $11+3 \pm 1.5$ in cases $(n=129)$ and $11+2 \pm 1.3$ in control $(\mathrm{n}=129),(\mathrm{P}=0.50)$. This can be interpreted by different study points with no statistical difference between both groups.

In the present study, the mean crown crump length in cases group was $22.86 \pm 8.70$ while in control group the mean crown rump length was $26.50 \pm 5.47$. There was no statistically significant difference between cases group and control group. Similar results were obtained by Gordon et al. [14], with CRL average of $12 \mathrm{wk} 5 \mathrm{~d} \pm 3$ $\mathrm{d}(\mathrm{p}=0.482)$. While Rolo et al. ${ }^{[15]}$ reported mean CRL of $23.4 \mathrm{~mm} \pm 7.9 \mathrm{SD}$ ranging from 9 to $40 \mathrm{~mm}$. This study was conducted on normal pregnancies between 7- and 10-weeks' gestation.

In the present study, it was found that the mean gestational sac volume in study group cases was38.93 \pm 13.30 while in control group it was $38.60 \pm 15.48$. There was no statistically significant difference. These results agree with Hoopmann et al. [16] After controlling the CRL effect, the placental, gestational sac and fetal volumes were not significantly different between the SGA and AGA group (AGA is a condition in which a fetus or newborn infant size is within the normal range for gestational age).

In the current study, the mean yolk sac volume in study group cases was $0.12 \pm 0.05$ while in control group the mean yolk sac volume was $0.15 \pm 0.09$. There was no statistically significant difference between study cases and control group. A yolk sac diameter of greater than $5 \mathrm{~mm}$ indicated a 3-fold increased risk for firsttrimester loss, independent of maternal risk factors ${ }^{[4]}$. In Moradan and Forouzeshfar ${ }^{[10]}$, with regards to yolk sac characteristics of the control group, the sac diameters ranged from 2-4.9 $\mathrm{mm}$, all of which had a round shape. While in study group $(50 \%)$ had yolk sacs that were greater than $5 \mathrm{~mm}$; the largest was 9.2 mm. In Bae and Karnitis ${ }^{[17]}$ study, the ongoing pregnancy rate was much greater in the group in which 
the yolk sac diameter (YSD) ranged from 2 to $6 \mathrm{~mm}$ than that in groups in which the YSD was either less than $2 \mathrm{~mm}$ or greater than $6 \mathrm{~mm}(\mathrm{OR}=33.1, \mathrm{P}<0.001)$. Their results were not consistent to our findings due to difference in mean gestational age between the two studies.

In the present study, as regards Doppler, (RI) of the retro chorionic arteries in studied cases group was $0.48 \pm 0.09$ while in control group was $0.44 \pm 0.07$. There was highly statistically significant increase in studied cases group compared to control group. This was interpreted in Roberts et al. ${ }^{[18]}$ study reporting that spiral artery remodeling, by the end of the first trimester, the radial arteries are smaller than the spiral arteries.

Regarding ultrasound findings in continued study cases and continued control, it was found that in continued study cases; the mean CRL was 22.86 \pm 8.70 ; the mean GSV was $38.93 \pm 13.30$; the mean YSV was $0.12 \pm 0.05$ and the mean retro Chorionic Arteries (RI) was $0.48 \pm 0.09$. In continued control, the mean CRL was $26.50 \pm 5.47$; the mean GSV was $38.60 \pm 15.48$; the mean YSV was $0.12 \pm 0.05$; the mean retro Chorionic Arteries (RI) was $0.44 \pm 0.07$. There was statistically significant difference between cases group and control group according to RI. In agreement with the current results, Odeh et al. [19] found that GSV was significantly larger in normal pregnancies than in missed or anembryonic abortion: $27.51+$ or $-25.25 \mathrm{~cm}$ (3) and $8.04+$ or $-10.54 \mathrm{~cm}$ (3), respectively ( $\mathrm{p}<$ 0.001). Also, these results agree with Rashid et al. [20] study with a mean z-score of CRL was significantly lower in the miscarriage group of women compared with continued viable pregnancy group ( -1.43 vs. $0.80, \mathrm{P}=0.030$ ).

In the current study, ROC curve was used to define the area under the curve of retro chorionic arteries (RI); the cut-off value was $>0.513$; sensitivity was $84 \%$, specificity was $83 \%$; PPV was $83.2 \%$; NPV was $83.8 \%$ and AUC was $83.5 \%$. RI represents the most important indicator. These results differ from Özkan et al. ${ }^{[21]}$ study results; they determined uterine and spiral artery blood flow changes in first trimester subsequent miscarriages and correlate within the mechanisms of the Doppler indices. The area under the receiver operating characteristic curve for spiral artery pulsatility index was $0.561(\mathrm{P}=0.064,95 \% \mathrm{CI}: 0.435-$ 0.687 ). Sensitivity was $78 \%$, PPV was $38 \%$ and NPV was $97 \%$. Considering that the measurement variation may relate to different US devises and different operators. Suguna and Sukanya ${ }^{[22]}$ examined 500 pregnant women between $6+0$ and $9+6$ weeks of conception. They found that the diameter of Yolk sac (sensitivity and specificity were $62.3 \%$ \& $64.1 \%$ and the diameter of PPV and NPV was $27.3 \%$ and $88.7 \%$, respectively). Results of Odeh et al. ${ }^{[19]}$ found that the area under the curve of the gestational sac (GSV) volume (ASV)-amniotic sac volume (ASV) measuring area was 0,654 for prediction of normal pregnancy. Abortion with sensitivity of $84 \%$ and $43 \%$ specificity is forecast when the GSV-ASV was $1.8 \mathrm{~cm}$ (3) or lower. They concluded that the prediction for GSV ASV use could be unhelpful.

In predicting adverse results of twin pregnancies, Johansen et al. [23] assessed the usefulness of the discord in the first trimester (CRL). For each outcome, curves have been created for the receiver operating characteristics. For CRL discordance $\geq 10 \%$ as a predictor of fetal loss and preterm delivery in dichorionic twin pregnancies, sensitivity was 0.17 (95\% CI, 0.06-0.28) and 0.14 (95\% CI, 0.10-0.18), respectively, and in monochorionic twin pregnancies it was 0.10 (95\% CI, 0.03-0.22) and 0.16 (95\% CI, 0.06$0.26)$, respectively. This difference between our results and other studies is related to different populations, sample sizes and different demographic characteristics.

\section{CONCLUSION}

The resistant index of retrochorionic arteries; GSV and YSV were good predictors of pregnancy outcome in the first trimester as confirmed by ROC curve for the Doppler indices. Those parameters can be helpful in selecting high risk pregnancies. We recommend improving understanding of the clinicians about how to counsel parents regarding early pregnancy complications based on information provided by threedimensional ultrasound is essential.

\section{Future directions}

- Further studies are needed with larger sample sizes to identify prognostic indicators of adverse pregnancy outcome.

Conflicts of interest: No conflicts of interest. Financial support: No financial support.

\section{REFERENCES}

1. Ryou H, Yaqub $M$, Cavallaro A, Papageorghiou AT, Alison Noble J. Automated 3D ultrasound image analysis for first trimester assessment of fetal health. Phys Med Biol 2019; 64 (18): 185010.

2. Kaur A and Kaur A. Transvaginal ultrasonography in first trimester of pregnancy and its comparison with transabdominal ultrasonography. J.Pharm. Bioallied. Sci 2011;3(3): 329-338.

3. Levi CS and Lyons EA. Yolk sac number, size and morphologic features in monochorionic monoamniotic twin pregnancy. In: Rumack CM, Levine D (eds). Diagnostic Ultrasound E-Book. Chapter 30: The First Trimester, 5th edn. Philadelphia, PA: Elsevier, 2018; 1048-1087.

4. Berdahl DM, Blaine J, Van Voorhis B, Dokras A. Detection of enlarged yolk sac on early ultrasound is associated with adverse pregnancy outcomes. FertilSteril 2010; 94(4):1535-1537.

5. Butt $\mathbf{K}$ and Lim K. Determination of gestational age by ultrasound. J ObsGynaecol Can 2014;36: $171-183$. 
6. Nguyen NC, Evenson KR, Savitz DA, Chu H, Thorp JM, Daniels JL. Physical activity and maternal-fetal circulation measured by Doppler ultrasound. J Perinatol 2013; 33(2):87-93.

7. Balsane R, Vyas J, Rajoria L, Agarwal $\mathbf{P}$, Gupta S. To study the association between initial fetal crown-rump length and subsequent abortion in a viable first trimester pregnancy. Int $\mathrm{J}$ Reprod Contracept Obstet Gynecol 2016; 5:1744-7.

8. Oates J, Casikar I, Campain A, Müller S, Yang J, Reid S, Condous G. A prediction model for viability at the end of the first trimester after a single early pregnancy evaluation. J. ObstetGynecol 2013;53(1):51-57.

9. Tudorache Ş, Căpitănescu RG, Drăgușin RC, Zorilă, GL, Marinaș, MC, Cernea, et al. Implications of the First Trimester $2 \mathrm{~d}$ and $3 \mathrm{~d}$ Ultrasound in Pregnancy Outcome. Curr Health Sci J 2019; 45(3):311-315.

10. Moradan $\mathbf{S}$ and Forouzeshfar M. Are abnormal yolk sac characteristics important factors in abortion rates? Int J FertilSteril 2012; 6(2):127130.

11. Bellver J, Rossal LP, Bosch E, Zúñiga A, Corona JT, Meléndez F, Gómez E, Simón C, Remohí J, Pellicer A. Obesity and the risk of spontaneous abortion after oocyte donation. FertilSteril 2003; 79(5):1136-40.

12. Alemu A, Abebe M, Biadgo B, Terefe B, Baynes HW. Biochemical Profiles of Pregnant and Nonpregnant Women Attending at the University of Gondar Hospital, Northwest Ethiopia: A Comparative Cross-sectional Study. Ethiop J Health Sci 2018; 28(3):331-340.

13. Kazemier BM, Kleinrouweler CE, Oudijk MA, van der Post JA, Mol BW, Vis JY, Pajkrt E. Is short first-trimester crown-rump length associated with spontaneous preterm birth? Ultrasound ObstetGynecol 2012; 40(6):636-41.

14. Gordon GH, Antony KM, Sampene E, Iruretagoyena JI. Maternal obesity is not associated with increased crown-rump length in first-trimester ultrasounds of singleton gestations. J Matern Fetal Neonatal Med 2019; 32(14):23932399.
15. Rolo LC, Nardozza LM, Araujo Júnior E, Nowak PM, Moron AF. Gestational sac volume by 3D-sonography at 7-10 weeks of pregnancy using the VOCAL method. Arch GynecolObstet 2009; 279(6):821-7.

16. Hoopmann M, Schermuly S, Abele H, Zubke W, Kagan KO. First trimester pregnancy volumes and subsequent small for gestational age fetuses. Arch GynecolObstet, 2019; 290(1):41-6.

17. Bae $\mathbf{S}$ and Karnitis J. Triple ultrasound markers including fetal cardiac activity are related to miscarriage risk. FertilSteril, 2011; 96(5):1145-8.

18. Roberts VHJ, Morgan TK, Bednarek P, Morita M, Burton GJ, Lo JO, Frias AE. Early first trimester uteroplacental flow and the progressive disintegration of spiral artery plugs: new insights from contrast-enhanced ultrasound and tissue histopathology. Hum Reprod 2017; 32(12):23822393.

19. Odeh M, Ophir E, Grinin V, Tendler R, Kais M, Bornstein J. Prediction of abortion using three-dimensional ultrasound volumetry of the gestational sac and the amniotic sac in threatened abortion. J Clin Ultrasound. 2012; 40(7):389-393.

20. Rashid H, Ma E, Ferdous F, Ekström EC, Wagatsuma Y: First-trimester fetal growth restriction and the occurrence of miscarriage in rural Bangladesh: A prospective cohort study. PLoSOne 2017; 12(7): e0181967.

21. Özkan MB, Ozyazici E, Emiroglu B, Özkara E. "Can we measure the spiral and uterine artery blood flow by real-time sonography and Doppler indices to predict spontaneous miscarriage in a normal-risk population?" Australasian Journal of Ultrasound in Medicine 2015; 18(2): 60-66.

22. Suguna B and Sukanya K. Yolk sac size \& shape as predictors of first trimester pregnancy outcome: A prospective observational study. J GynecolObstet Hum Reprod 2019; 48(3):159-164.

23. Johansen ML, Oldenburg A, Rosthøj S, Cohn Maxild J, Rode L, Tabor A. Crown-rump length discordance in the first trimester: a predictor of adverse outcome in twin pregnancies?. Ultrasound Obstet Gynecol 2014 


\section{الماخص العربي}

دور قياس كيس الحمل والحويصلة السرية وتدفق الام الرجعي بواسطة الموجات فوق الصوتية ثلاثية الأبعاد

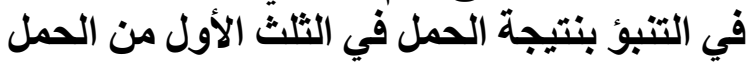

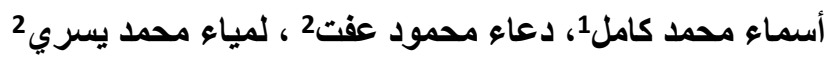

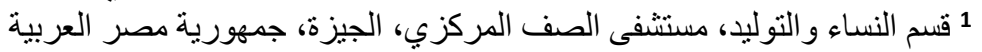

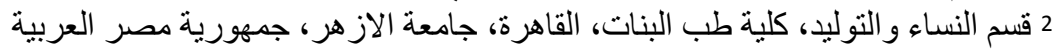

ملخص البحث

الخلقية: يمكن استخدام الموجات فوق الصوتية ثلاثية الأبعاد لتقييم مخاطر الحمل في الثلث الاول من الحمل الهدف: كان الهدف من هذه الدراسة هو تحديد دور قياس كبس الحمل والحويصلة السرية وتدفق الدم الرجعي بواسطة الموجات فوق الصونية ثناثية الأبعاد في التنبؤ بنتيجة الحمل في الثلث الأول من التئ الحمل. الطرق: أجريت هذه الدراسة الحثدية في مستشفى الزهر اء الجامعي وضمت (100) امر أة حامل ثتراوح

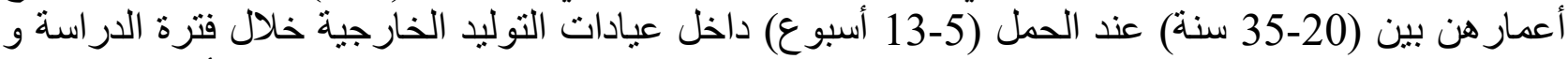

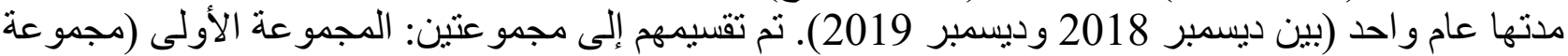

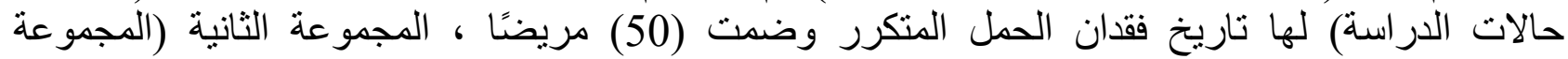

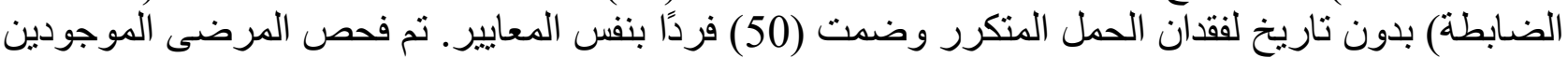
في الدر اسة بالموجات فوق الصوتية ثناثية الأبعاد وبعد ذلك تمت متابعتهم حتى عشرين أسبو عًا للتنبؤ بنتيجة الحمل.

النتائج: تم استخدام منحنى خصائص التشغيل لتحديد المنطقة تحت منحنى الثر ايين المشيمية الرجعية وكانت الحساسية (84.0 \%) ؛ و الحساسية في حجم كيس الحمل (77 \%) ؛ حجم الحويصلة السرية (71.0\%) و الطول التاجي المقعدي (52.0\%)

الاستنتاج: توفر تقييمات الموجات فوق الصوتية في الأشهر الثلاثة الأولى من خلال حجم كيس الحمل وحجم

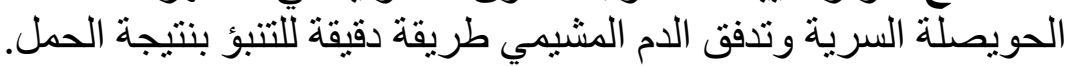

الكلمات المفتاحية :حجم كيس الحمل، الثر ايين المشيمية الرجعية، حجم الحويصلة السرية، نتيجة الحمل، الموجات فوق الصوتية

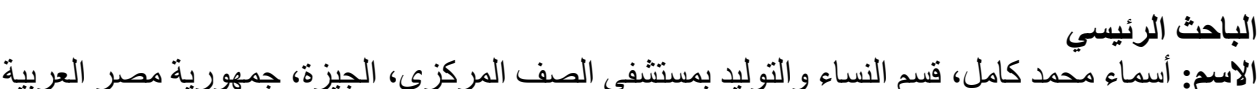

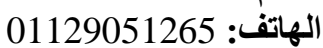
البريد الإكتروني:asmaaeyadroma@gmail.com 